\title{
ANALISIS KINERJA STRUKTUR BETON BERTULANG DENGAN VARIASI PENEMPATAN BRACING INVERTED V
}

\author{
Julita Andrini Repadi ${ }^{1}$, Jati Sunaryati ${ }^{2}$, dan Rendy Thamrin ${ }^{3}$
}

\begin{abstract}
ABSTRAK
Pada studi ini dilakukan analisis terhadap kinerja struktur beton bertulang 4 lantai dengan variasi penempatan bracing inverted $V$. Analisis dilakukan dengan perangkat lunak ETABS V9.7.1 Hasil analisanya akan dibandingkan struktur beton bertulang tanpa bracing dengan struktur beton bertulang yang diberi variasi penempatan bracing. Melalui studi ini dilakukan analisis perbandingan displacement, daktilitas, dan kinerja struktur pada bangunan beton bertulang 4 lantai. Berdasarkan hasil analisis dapat diambil kesimpulan bahwa perkuatan dengan bracing mampu mengurangi nilai displacement, dan daktilitas struktur beton bertulang. Penurunan bracing mengurangi periode struktur bangunan, pengurangan nilai displacement pada arah $\mathrm{X}$ sebesar $1.328 \%-42.013 \%$, arah Y sebesar $10.00 \%-39.394 \%$. Nilai daktilitas struktur mengalami peningkatan dibandingkan dengan gedung tanpa perkuatan bracing. Taraf kinerja struktur bangunan aman. Hal ini menunjukkan bahwa penggunaan bracing dapat meningkatkan kekakuan, kekuatan dan stabilitas struktur.
\end{abstract}

Kata kunci : struktur beton bertulang, kinerja, daktilitas.

\section{PENDAHULUAN}

Salah satu alternatif yang diusulkan untuk meramalkan kinerja pada saat gempa besar adalah menggunakan analisis statis nonlinier yang diberi nama Analisis Beban Dorong Statik (Static Pushover Analysis), dimana analisisnya lebih sederhana dan mampu menggambarkan perilaku inelastis setiap komponen struktur.

Dengan menggunakan metode pushover analisis akan diperoleh perilaku struktur secara keseluruhan, dari elastis, leleh dan akhirnya runtuh, yaitu dengan cara struktur didorong secara bertahap dengan menaikkan faktor pengali sampai struktur tersebut leleh dan berdeformasi inelastis. Analisa menghasilkan kurva pushover atau kurva kapasitas yang menggambarkan hubungan antara gaya geser (V) dengan perpindahan titik acuan pada atap (D). Untuk menghindari terjadinya keruntuhan bangunan, panjang bentang diperkecil dengan cara memasang pengaku (bracing) pada arah sumbu lemah kolom. Batang pengaku (bracing) merupakan salah satu komponen struktur yang berfungsi untuk menambah kekuatan dan kekakuan struktur sehingga secara efektif dapat mengurangi simpangan pada suatu bangunan. Penggunaan bracing dapat mengurangi waktu getar alami struktur. Massa bangunan dan kekakuan akan berpengaruh pada waktu getar alami. Hal ini disebabkan karena massa bangunan akan bertambah besar karena adanya bracing, jarak antar balok atau kolom menjadi

\footnotetext{
${ }^{1}$ Mahasiswa Pasca Sarjana Teknik Sipil Universitas Andalas, julitaandrinirepadi@gmail.com

${ }^{2}$ Staf Pengajar Jurusan Teknik Sipil Fakultas Teknik Universitas Andalas, jati@ft.unand.ac.id

${ }^{3}$ Staf Pengajar Jurusan Teknik Sipil Fakultas Teknik Universitas Andalas, rendy@ft.unand.ac.id
} 
lebih kecil sehingga kekakuannya menjadi lebih besar ini akan menyebabkan waktu getar alami struktur menggunakan bracing akan berkurang di bandingkan struktur tanpa menggunakan bracing.

\section{BRACING}

Bracing adalah metode pengaku struktur bangunan yang berfungsi menambah kekakuan bangunan, menahan beban lateral, menambah daktilitas dan kekuatan serta mampu meredam energi yang di akibatkan getaran-getaran. Bracing terbagi menjadi 2 macam yaitu Bracing Vertikal Eksentrik (Eccentrically Braced Frame), dimana masing-masing bracing akan terhubung dengan balok dan Bracing Vertikal Konsentrik (Consentrically Braced Frame) dimana sumbu utamanya bertemu atau saling memotong dalam satu titik Struktur Bracing. Struktur Bracing Inverted V merupakan salah satu jenis dari Bracing Vertikal Konsentrik, kedua batang diagonal akan sama-sama menahan beban horizontal. Beban gravitasi juga mengakibatkan gaya aksial bracing inverted $V$. Ketika bracing ini menahan balok pada tengan bentang, akan mengurangi bentang balok efektif dan kapasitas momen yang terjadi. Kerugian bracing inverted $V$ yaitu memiliki bentang yang lebih panjang bila dibandingkan dengan bracing diagonal, bracing juga harus menahan beban gravitasi. Keuntungan bracing inverted $V$ yaitu kedua batang sama-sama memikul beban horizontal, Secara arsitektural memungkinkan adanya pintu, jendela atau bagian terbuka ditengah bentang, dapat mengurangi profil dimensi balok sehingga secara ekonomi lebih menguntungkan.

\section{PERMODELAN STRUKTUR}

Bentuk bangunan simetris dengan deskripsi sebagai berikut : Lokasi bangunan : Kota Padang, Jenis tanah : Lunak, Jenis Struktur : Beton Bertulang, Mutu Beton : $30 \mathrm{MPa}$, Mutu Baja Tulangan : 400 $\mathrm{MPa}$, Fungsi bangunan : perkantoran, Jumlah lantai : 4 lantai, Tinggi lantai $1: 4$ meter, tinggi lantai 2,3, dan $4: 3.5$ meter, Tinggi total : 14,5 meter, Luas Lantai : $45 \mathrm{~m}$ x $25 \mathrm{~m}: 1125 \mathrm{~m}^{2}$, Jarak Kolom : 5 meter, Pembebanan yang diberikan : Beban gempa Dinamis Time History El Centro, beban mati, dan beban hidup. Dimensi kolom lantai 1,2,3,4:(30x30)cm, balok : $(20 \times 30) \mathrm{cm}$, plat lantai : $12 \mathrm{~cm}$, Tipe bracing : Inverted V,baja profil IWF 250.250.9.14. Denah model struktur tanpa bracing, variasi penempatan bracing 1, variasi penempatan bracing 2 terlihat pada Gambar (3.1). Permodelan 3 dimensi model struktur dengan variasi penempatan bracing 1 dan variasi penempatan bracing 2 dapat terlihat pada Gambar (3.2)

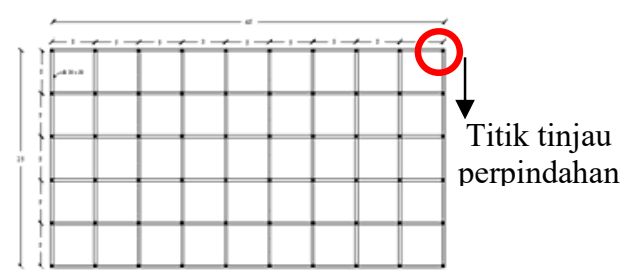

(a)

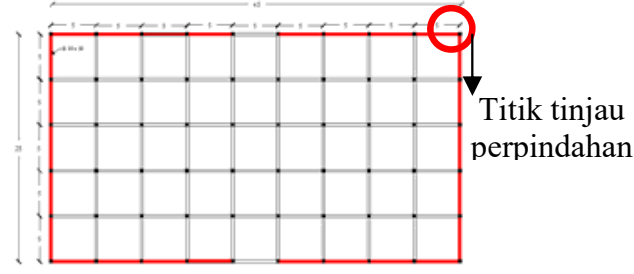

(b)

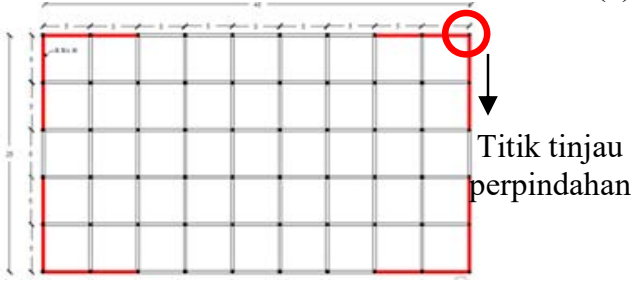

(c)

Gambar 3.1 Denah Model Struktur (a) Tanpa Bracing (b) Dengan Variasi Penempatan Bracing 1 (c) Dengan Variasi Penempatan Bracing

VOLUME 12 NO. 2, OKTOBER 2016 | 33 


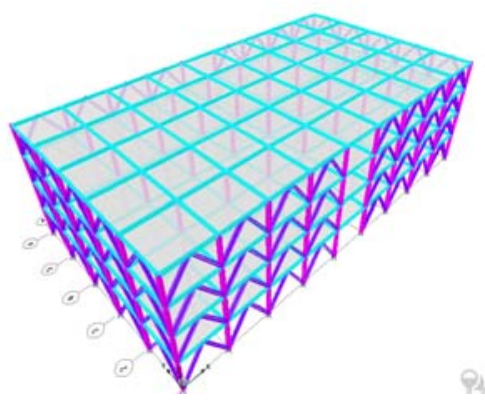

(a)

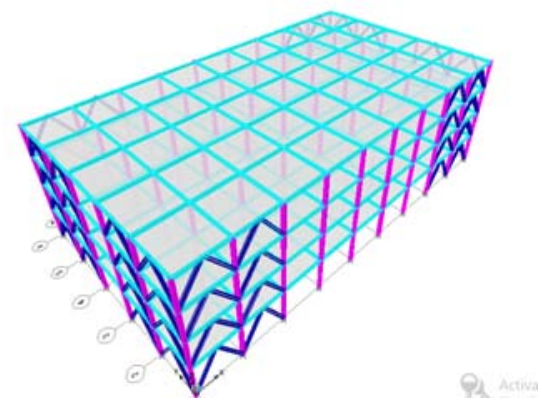

(b)

Gambar 3.2 Permodelan 3 Dimensi Struktur (a) Dengan Variasi Penempatan Bracing 1 (b) Dengan Variasi Penempatan Bracing 2

Tahap-tahap pekerjaan pada studi ini adalah sebagai berikut, studi kasus dilakukan terhadap permodelan struktur bangunan bertingkat 4 lantai tanpa menggunakan bracing, setelah itu dilakukan analisis modal untuk menghitung waktu getar alami, ragam getar, faktor efektivitas massa dan nilai base shear dari permodelan struktur bangunan yang merupakan dasar struktur untuk perhitungan analisis riwayat waktu, kemudian, dilakukan permodelan struktur bangunan bertingkat 4 lantai dengan menggunakan bracing yaitu variasi penempatan bracing 1 dan variasi penempatan bracing 2, Running analisis (Analisis Pushover), pada tahap ini dilakukan perbandingan displacement, pengaruh bracing terhadap daktilitas struktur dan kinerja struktur struktur tanpa bracing dan dengan bracing. Pada tahap akhir dari penelitian ini diharapkan nantinya ada suatu kesimpulan dan saran berdasarkan hasil yang diperoleh.

\section{HASIL DAN PEMBAHASAN}

Struktur dianalisa gempa dinamik dengan menggunakan bantuan perangkat lunak komputer/Software ETABS V.9.0 untuk mengetahui waktu getar alami.

Waktu Getar Alami Maksimum dari Struktur Gedung (To)

$$
\begin{aligned}
\text { To } & =\text { Ct. } \mathrm{h}^{\mathrm{x}} \\
& =0.0466 \times 14,5^{0.9} \\
& =0,60813 \mathrm{dt}
\end{aligned}
$$

Dimana :

$$
\begin{array}{ll}
\mathrm{T}(\mathrm{a}) & =\text { Periode pendekatan fundamental } \\
\mathrm{Ct} \text { dan } \mathrm{x} & =\text { Koefisien batas periode fundamental } \\
\mathrm{h} & =\begin{array}{l}
\text { Ketinggian struktur, dalam } \mathrm{m} \text {, di atas dasar sampai tingkat tertinggi } \\
\text { struktur }
\end{array}
\end{array}
$$

Untuk waktu getar alami hasil analisis modal untuk model struktur tanpa bracing menggunakan program ETABS adalah $\mathrm{To}=1.0074$

Analisis Modal Model 1

Persyaratan :

Periode struktur menggunakan program ETABS 1.0074
$<$ Waktu getar alami maksimum dari struktur gedung (To)

$>0.60813$

34 | JURNAL REKAYASA SIPIL 
Dari Tabel di atas dapat disimpulkan bahwa nilai waktu getar alami tanpa menggunakan bracing belum memenuhi persyaratan yang berlaku dalam SNI 1726.2012.

Perpindahan Model 1

Perpindahan pada struktur dapat ditinjau pada salah satu joint di struktur. Tabel dibawah menjelaskan tentang simpangan antar lantai pada permodelan model struktur tanpa bracing.

Tabel 4.1 Kontrol Simpangan Antar Lantai Gedung Model 1 Pada Arah X

\begin{tabular}{|c|c|c|c|c|c|}
\hline Lantai & Tinggi Lantai & Drift Story (m) & X Direction & $\Delta \boldsymbol{a}=\mathbf{0 . 0 2 5 H} / \boldsymbol{\rho}$ & \multirow{2}{*}{$\Delta \boldsymbol{s}<\boldsymbol{\Delta}$} \\
\cline { 3 - 5 } & & & $\Delta \boldsymbol{s}=\boldsymbol{D} \boldsymbol{x C d} / \mathbf{I} \boldsymbol{e}$ & & \\
\hline 1 & 4 & 0.005 & 0.028 & 0.076 & OK \\
\hline 2 & 3.5 & 0.007 & 0.041 & 0.067 & OK \\
\hline 3 & 3.5 & 0.009 & 0.050 & 0.067 & OK \\
\hline 4 & 3.5 & 0.011 & 0.062 & 0.07 & OK \\
\hline
\end{tabular}

Berdasarkan Tabel 4.1 hasil analisis simpangan antar lantai pada arah X desain pada lantai 1, 2, 3, dan 4 masih memenuhi persyaratan simpangan antar lantai izin.

Tabel 4.2 Kontrol Simpangan Antar Lantai Gedung Model 1 Pada Arah Y

\begin{tabular}{|c|c|c|c|c|c|}
\hline Lantai & Tinggi Lantai & Drift Story (m) & $\mathbf{X}$ Direction & $\boldsymbol{\Delta} \boldsymbol{a}=\mathbf{0 . 0 2 5 H} / \boldsymbol{\rho}$ & \multirow{2}{*}{$\boldsymbol{s}<\Delta \boldsymbol{a}$} \\
\cline { 4 - 5 } & & & $\Delta \boldsymbol{s}=\boldsymbol{D} \boldsymbol{x} \boldsymbol{C d} / \boldsymbol{I} \boldsymbol{e}$ & & \\
\hline 1 & 4 & 0.018 & 0.066 & 0.076 & OK \\
\hline 2 & 3.5 & 0.023 & 0.129 & 0.067 & NOT OK \\
\hline 3 & 3.5 & 0.033 & 0.181 & 0.067 & NOT OK \\
\hline 4 & 3.5 & 0.039 & 0.214 & 0.07 & NOT OK \\
\hline
\end{tabular}

Berdasarkan Tabel 4.2 hasil analisis simpangan antar lantai pada arah Y desain pada lantai 1 masih memenuhi persyaratan simpangan antar lantai izin, sedangkan pada lantai 2, 3, dan 4 sudah tidak memenuhi persyaratan simpangan antar lantai izin.

Kesimpulan Analisis Model 1

Dari hasil analisis modal struktur terhadap peraturan gempa SNI 03-1726-2012, diperoleh nilai waktu getar alami yang tidak memenuhi persyaratan, sehingga struktur gedung perlu dilakukan perkuatan dengan menggunakan bracing. Sedangkan untuk simpangan antar lantai izin lantai 2,3 dan 4 tidak memenuhi persyaratan simpangan antar lantai izin.

Analisis Modal Model 2 dan Model 3

\begin{tabular}{|c|c|c|}
\hline Persyaratan : & $\begin{array}{l}\text { Periode struktur }< \\
\text { menggunakan } \\
\text { program ETABS }\end{array}$ & $\begin{array}{l}\text { Waktu getar alami } \\
\text { maksimum dari struktur } \\
\text { gedung (To) }\end{array}$ \\
\hline Mo & 0.256 & 0.60813 \\
\hline Model 3 & 0.305 & 0.60813 \\
\hline
\end{tabular}

Dari Tabel di atas dapat disimpulkan bahwa nilai waktu getar alami dengan menggunakan bracing telah memenuhi persyaratan yang berlaku dalam SNI 03.1726.2012.

Perpindahan (Displacement) Model 2 dan Model 3

Perpindahan pada struktur dapat ditinjau pada salah satu joint di struktur. Grafik dibawah menjelaskan tentang bagaimana pengaruh perkuatan bracing (model 2 dan model 3) di bandingkan model 1(tanpa perkuatan bracing) 
Tabel 4.3 Perbandingan Perpindahan Maksimum Arah X Joint 20

\begin{tabular}{|c|c|c|c|c|c|c|}
\hline \multirow[b]{2}{*}{ Lantai } & \multirow[b]{2}{*}{ Titik } & \multicolumn{3}{|c|}{ Displacement (mm) } & \multirow{2}{*}{$\begin{array}{c}\text { Presentase } \\
\text { Beda Model } \\
1 \text { \& Model } 2\end{array}$} & \multirow{2}{*}{$\begin{array}{l}\text { Presentase } \\
\text { Beda Model } \\
1 \text { \& Model } 2\end{array}$} \\
\hline & & Model 1 & Model 2 & Model 3 & & \\
\hline 1 & 20 & 5,27 & 3,50 & 5,20 & 33,586 & 1,328 \\
\hline 2 & 20 & 7,55 & 4,70 & 6,21 & 37,748 & 17,748 \\
\hline 3 & 20 & 9,14 & 5,30 & 7,56 & 42,013 & 17,287 \\
\hline 4 & 20 & 11,3 & 8,00 & 9,89 & 29,204 & 12,478 \\
\hline
\end{tabular}

Tabel 4.4 Perbandingan Perpindahan Maksimum Arah Y Joint 20

\begin{tabular}{|c|c|c|c|c|c|c|}
\hline \multirow{2}{*}{ Lantai } & Titik & Model 1 & Model 2 & Model 3 & $\begin{array}{c}\text { Presentase } \\
\text { Beda Model 1 } \\
\& \text { Model 2 }\end{array}$ & $\begin{array}{c}\text { Presentase } \\
\text { Beda Model 1 } \\
\& \text { Model 2 }\end{array}$ \\
\cline { 3 - 6 } & 20 & 18,00 & 11,00 & 13,00 & 38,889 & 27,778 \\
\hline 1 & 20 & 23,50 & 18,00 & 20,90 & 23,404 & 11,064 \\
\hline 2 & 20 & 33,00 & 20,00 & 29,70 & 39,394 & 10,000 \\
\hline 4 & 20 & 39,00 & 25,00 & 32,70 & 35,897 & 16,154 \\
\hline
\end{tabular}

Berdasarkan Tabel 4.3 dan Tabel 4.4 Pada joint 20 arah x dari lantai 1- lantai 4 pada perbandingan struktur tanpa bracing (model 1) dengan perkuatan bracing (model 2) mengalami pengurangan nilai perpindahan pada arah x berkisar $29.204 \%-42.013 \%$ dan pada arah y berkisar 23,404\%-39,394\%. Sehingga dapat diketahui bahwa pengaruh perkuatan bracing sangat besar terhadap perpindahan struktur yang terjadi akibat adanya beban gempa. Sedangkan perbandingan (model 1) dengan perkuatan bracing (model 3) mengalami pengurangan nilai perpindahan pada arah $\mathrm{x}$ berkisar $1.328 \%-12.748 \%$ dan pada arah y berkisar $10,00 \%-27.778 \%$.

Untuk melihat perbandingan simpangan antar lantai struktur dengan dan tanpa perkuatan bracing dilakukan sebuah kontrol yang sesuai dengan peraturan gempa SNI 1726-2012.

Tabel 4.5 Kontrol Simpangan Antar Lantai Gedung Model 2 Pada Arah X

\begin{tabular}{|c|c|c|c|c|c|}
\hline Lantai & Tinggi Lantai & Drift Story (m) & $\mathbf{X}$ Direction & $\Delta \boldsymbol{a}=\mathbf{0 . 0 2 5 H} / \boldsymbol{\rho}$ & \multirow{2}{*}{$\boldsymbol{s}<\Delta \boldsymbol{a}$} \\
\cline { 4 - 5 } & & & $\Delta \boldsymbol{s}=\boldsymbol{D} \boldsymbol{x} \boldsymbol{C d} / \boldsymbol{I} \boldsymbol{e}$ & & \\
\hline 1 & 4 & 0.003 & 0.012 & 0.076 & OK \\
\hline 2 & 3.5 & 0.004 & 0.017 & 0.067 & OK \\
\hline 3 & 3.5 & 0.005 & 0.019 & 0.067 & OK \\
\hline 4 & 3.5 & 0.008 & 0.029 & 0.07 & OK \\
\hline
\end{tabular}

Tabel 4.6 Kontrol Simpangan Antar Lantai Gedung Model 2 Pada Arah Y

\begin{tabular}{|c|c|c|c|c|c|}
\hline \multirow{2}{*}{ Lantai } & \multirow{2}{*}{ Tinggi Lantai } & Drift Story (m) & $\mathbf{X}$ Direction & $\Delta \boldsymbol{a}=\mathbf{0 . 0 2 5 H} / \boldsymbol{\rho}$ & \multirow{2}{*}{$\boldsymbol{s}<\Delta \boldsymbol{a}$} \\
\cline { 3 - 5 } & & & $\Delta \boldsymbol{s}=\boldsymbol{D} \boldsymbol{x} \boldsymbol{C d} / \boldsymbol{I} \boldsymbol{e}$ & & \\
\hline 1 & 4 & 0.011 & 0.040 & 0.076 & OK \\
\hline 2 & 3.5 & 0.018 & 0.066 & 0.067 & OK \\
\hline 3 & 3.5 & 0.02 & 0.073 & 0.067 & NOT OK \\
\hline 4 & 3.5 & 0.025 & 0.091 & 0.07 & NOT OK \\
\hline
\end{tabular}

Tabel 4.7 Kontrol Simpangan Antar Lantai Gedung Model 3 Pada Arah X

\begin{tabular}{|c|c|c|c|c|c|}
\hline Lantai & \multirow{2}{*}{ Tinggi Lantai } & \multirow{2}{*}{ Drift Story (m) } & $\mathbf{X}$ Direction & $\Delta \boldsymbol{a}=\mathbf{0 . 0 2 5 H} / \boldsymbol{\rho}$ & \multirow{2}{*}{$\Delta \boldsymbol{s}<\Delta \boldsymbol{a}$} \\
\cline { 3 - 4 } & & & $\Delta \boldsymbol{s}=\boldsymbol{D} \boldsymbol{x C d} / \boldsymbol{I} \boldsymbol{e}$ & & \\
\hline 1 & 4 & 0.005 & 0.019 & 0.076 & OK \\
\hline 2 & 3.5 & 0.006 & 0.022 & 0.067 & OK \\
\hline 3 & 3.5 & 0.007 & 0.027 & 0.067 & OK \\
\hline 4 & 3.5 & 0.009 & 0.036 & 0.07 & OK \\
\hline
\end{tabular}


Tabel 4.8 Kontrol Simpangan Antar Lantai Gedung Model 3 Pada Arah Y

\begin{tabular}{|c|c|c|c|c|c|}
\hline Lantai & \multirow{2}{*}{ Tinggi Lantai } & \multirow{2}{*}{ Drift Story $(\mathbf{m})$} & $\mathbf{X}$ Direction & $\Delta \boldsymbol{a}=\mathbf{0 . 0 2 5 H} / \boldsymbol{\rho}$ & \multirow{2}{*}{$\Delta \boldsymbol{s}<\boldsymbol{a}$} \\
\cline { 3 - 5 } & & & $\Delta \boldsymbol{s}=\boldsymbol{D} \boldsymbol{x} \boldsymbol{C d} / \boldsymbol{I} \boldsymbol{e}$ & & \\
\hline 1 & 4 & 0.013 & 0.047 & 0.076 & OK \\
\hline 2 & 3.5 & 0.021 & 0.076 & 0.067 & NOT OK \\
\hline 3 & 3.5 & 0.029 & 0.108 & 0.067 & NOT OK \\
\hline 4 & 3.5 & 0.032 & 0.119 & 0.07 & NOT OK \\
\hline
\end{tabular}

Berdasarkan Tabel 4.5 dan 4.7 analisis simpangan antar lantai desain arah x pada lantai 1,2,3 dan 4 memenuhi persyaratan simpangan antar lantai izin. Berdasarkan Tabel 4.6 dan 4.8 hasil analisis simpangan antar lantai desain arah y pada lantai 1 masih memenuhi persyaratan simpangan antar lantai izin, sedangkan pada lantai 2, 3, dan 4 sudah tidak memenuhi persyaratan simpangan antar lantai izin. Pada analisis ini dapat diketahui bahwa pada gedung tanpa perkuatan bracing nilai simpangan berkurang jika di bandingkan dengan model tanpa bracing.

Daktilitas adalah kemampuan struktur atau komponennya untuk melakukan deformasi inelastis bolak-balik berulang di luar batas titik leleh pertama, sambil mempertahankan sejumlah besar kemampuan daya dukung bebannya.

Nilai daktilitas aktual struktur gedung, dengan persamaan berikut :

$$
\mu=\begin{aligned}
& \delta \mathrm{u} \\
& \delta \mathrm{y}
\end{aligned}
$$

Dimana :

$$
\begin{array}{lll}
\mu & = & \text { Daktilitas struktur } \\
\delta \mathrm{u} & = & \text { Peralihan atap pada saat leleh pertama } \\
\delta \mathrm{y} & = & \text { Peralihan atap pada saat kondisi ultimit atau target peralihan }
\end{array}
$$

Tabel 4.9 Perbandingan Daktilitas Arah X

\begin{tabular}{|c|c|c|c|}
\hline Model & Simpangan pada saat leleh (m) & Simpangan pada saat runtuh (m) & Daktilitas \\
\hline 1 & 0.003 & 0.0127 & 4.233 \\
\hline 2 & 0.0028 & 0.0496 & 17.714 \\
\hline 3 & 0.0084 & 0.0534 & 6.357 \\
\hline
\end{tabular}

Tabel 4.10 Perbandingan Daktilitas Arah Y

\begin{tabular}{|c|c|c|c|}
\hline Model & Simpangan pada saat leleh (m) & Simpangan pada saat runtuh (m) & Daktilitas \\
\hline 1 & 0.003 & 0.012 & 4.000 \\
\hline 2 & 0.0091 & 0.057 & 6.297 \\
\hline 3 & 0.0048 & 0.015 & 3.093 \\
\hline
\end{tabular}

Berdasarkan tingkat kinerja struktur dapat dihitung berdasarkan perbandingan antara roof drift (D) maksimum dengan ketinggian gedung $(\mathrm{H})$. Nilai roof drift ditentukan dari perpotongan antara Demand Spectrum dan Kurva Kapasitas. 


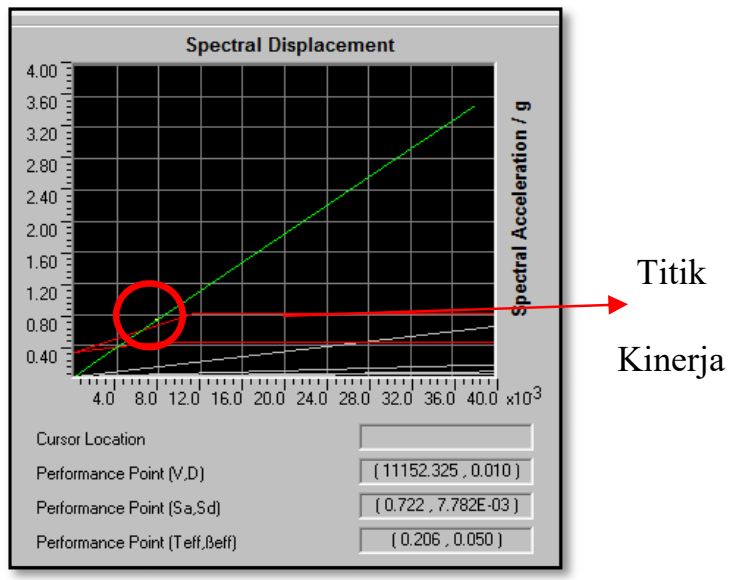

(a)

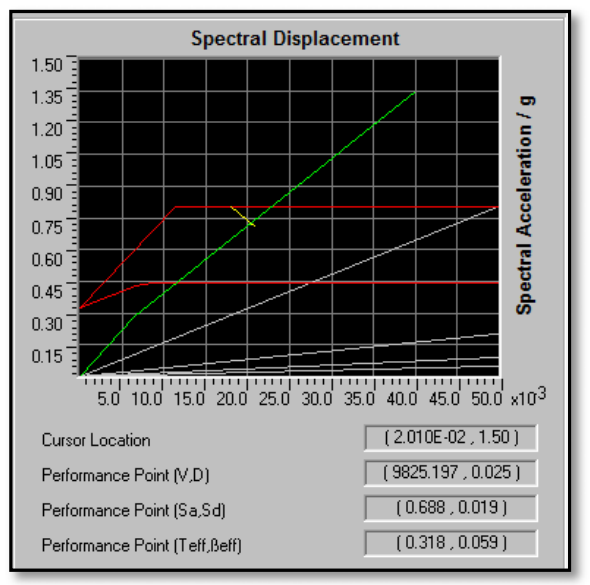

(c)

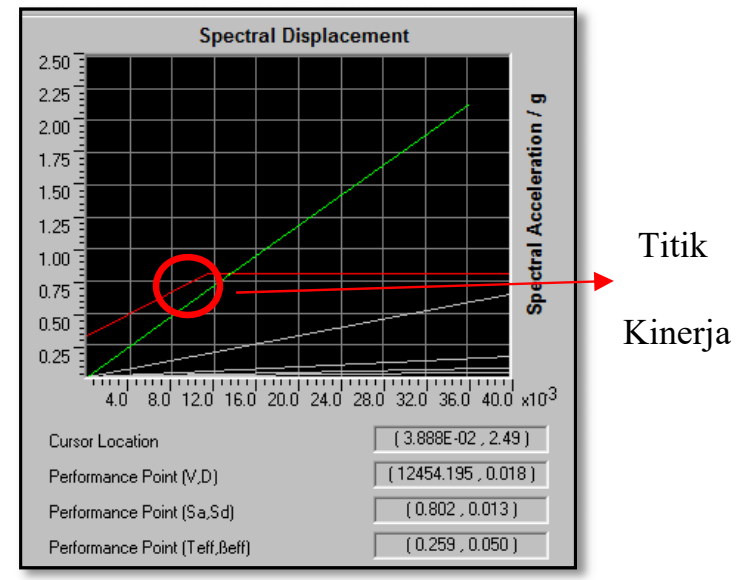

(b)

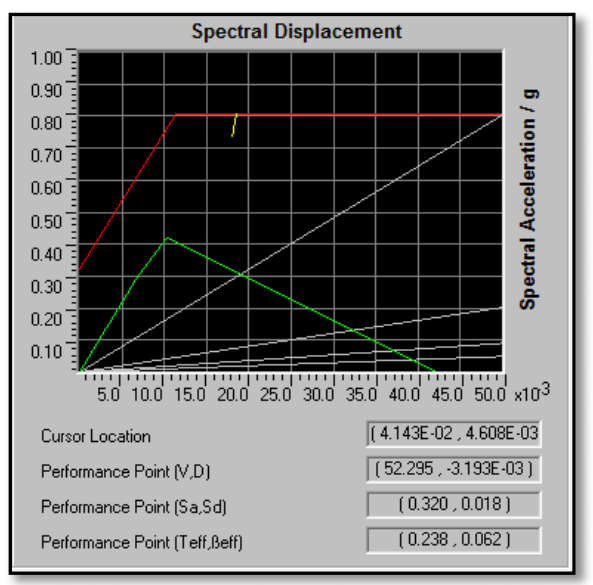

(d)

Gambar 4.1 Titik Kinerja pada struktur gedung (a) model 2 arah X, (b) model 2 arah Y, (c) model 3 arah X (d) model 3 arah Y

Hasil analisa pushover menunjukan bahwa permodelan memiliki roof drift (D) model 2 arah $\mathrm{X}$ sebesar $0.010 \mathrm{~m}$ dan arah Y sebesar $0.018 \mathrm{~m}$

Ketinggian gedung eksisting adalah 14,5 m sehingga nilai drift ratio dapat dihitung sebagai berikut :

Arah X

$$
\text { DriftRatio }=D / H=\frac{0.01}{14,5}=0.000689 \quad \text { Arah, } Y \quad \text { DriftRatio }=D / H=\frac{0.018}{14.5}=0.00124
$$

\section{Model 2}

IO ( Immediate Occupancy) dimana pada taraf kinerja ini struktur bangunan aman. Resiko korban jiwa dari kegagalan struktur tidak terlalu berat, gedung tidak mengalami kerusakan yang berarti dan dapat segera di fungsikan/beroperasi kembali setelah gedung mengalami gempa.

Model 3

Tingkat kinerja pada model 3 gedung dengan perkuatan bracing pada portal arah Y tidak memotong Demand Spectrum untuk kota Padang dengan kondisi Tanah Lunak sehingga tidak bisa diketahui kinerja struktur secara keseluruhan

\section{KESIMPULAN}

\section{8 | JURNAL REKAYASA SIPIL}


Berdasarkan penelitian terhadap kondisi gedung dengan perkuatan bracing (model 2 dan model 3) dan gedung tanpa perkuatan bracing dapat diambil kesimpulan :

1. Pemberian bracing dapat mengurangi periode struktur bangunan dan mampu mengurangi displacement struktur. Penurunan nilai displacement pada arah x sebesar 1,328\% - 42.013\%, arah Y sebesar 10.00\%-39.394\%.

2. Berdasarkan analisis pushover dapat dibuktikan bahwa nilai daktilitas struktur gedung dengan perkuatan bracing mengalami peningkatan dibandingkan dengan gedung tanpa perkuatan bracing.

3. Level kinerja struktur dengan perkuatan bracing model 2 adalah IO (Immediate Occupancy) dan model 3 dengan perkuatan bracing pada portal arah Y tidak memotong demand spectrum untuk kota Padang dengan kondisi tanah lunak sehingga tidak bisa diketahui kinerja struktur secara keseluruhan, perkuatan bracing pada kondisi gedung saat ini sangat membantu mengurangi besarnya respon struktur terhadap gaya gempa. Semakin banyak pemberian bracing maka pengaruh response structure juga semakin besar.

\section{DAFTAR PUSTAKA}

Departemen Permukiman dan Prasarana Wilayah, 2002, Standar Perencanaan Ketahanan Gempa Untuk Struktur Bangunan Gedung. SNI 1726 - 2002. Jurusan Teknik Sipil FTSP-ITB. Bandung 2002.

Direktorat Penyelidikan Masalah Bangunan. Peraturan Pembebanan Indonesia Untuk Gedung 1983. Yayasan Lembaga Penyelidikan Masalah Bangunan. Bandung. 1981.

Ediansyah, Zulkifli. 2010 "Perencanaan Bangunan Tahan Gempa" : Pelatihan Software ETABS Penerbit ITB Bandung

Iswandi, 2010, "Perencanaan Struktur Gedung Beton Bertulang Tahan Gempa" ITB, Bandung

SNI 03-1726-2012. 2012. “ Tata Cara Perencanaan Ketahan Gempa Struktur Bangunan Gedung dan Non Gedung”. BSNI : Jakarta 